\title{
A Distributed Cognitive Approach Towards Internet Communication using F-Test
}

\author{
Chaman Verma ${ }^{1}$, Rupinder Kaur ${ }^{2}$ \\ ${ }^{1}$ (Research Scholar, Department of Computer Science \& Engineering, JJT University, India) \\ ${ }^{2}$ (M-Tech Scholar, Department of Computer Science \& Engineering, Chandigarh University, India)
}

\begin{abstract}
Internet is supposed to be a powerful multi-purpose tool for information searching. A number of people of different ages; from teenagers to old persons use it for sharing ideas, knowledge, experiences, cultures and communication. Internet has brought technological advancement in academics where the mode and medium of studies and research have almost changed. The faculty and students use more of internet than any other source for their teaching and studies purpose. The aim of this paper is to statistically test the significant difference between thoughts of faculty towards internet usage using F-Test. The research is conducted using a structured questionnaire according to five Point Likert-scales. More than hundred samples have been collected from six different reputed institutions including both male and female faculty in Sirsa District. By Applying FTest on the samples reveals the scatteredness in thoughts of male faculty and female faculty towards the use of internet in their social, academic and personal lives.
\end{abstract}

Keywords: -F-test, mean, scatteredness, variance.

\section{INTRODUCTION AND RELATED WORK}

A report generated by Internet Society this year, tells that there are more than 3 billion people online today. The increasing use of smart phones, tablets in our day to day life has lead to adoption of internet at a faster rate [1]. According to another report released by the Internet and Mobile Association India (IAMAI) and IMRB International, India will have 402 million Internet users by December,2015; the second-largest Internet user base in the world [2]. A case study of the University of Kashmir by Tawfeeq Nazir reveals that majority of research scholars and students of science faculty are aware of e-journals, e-mails, e-maps, e-newspapers as compared to social science faculty. Users of Science faculty find e-resources as time saving and extra informative[3].A study conducted in Zimbabwean University academics tells that there is access to computers and the internet mainly from their university offices. An average of four hours per day is spending on internet for the academic purposes. University academics use Internet to write research papers, to prepare lectures and to update their main subject knowledge base [4]. A study in Barak Valley, South Assam showed that Internet is greatly used by college library users for their academic, classroom teaching, assignments and research[5].A study done in engineering colleges of Punjab, Haryana and Himachal Pradesh reveals that use of internet facility has enabled teachers to enhance their academic excellence by providing latest worldwide information [6].

The investigation done in institutions of Saudi Arabia has marked that faculty member's attitude is positive towards internet usage; internet adoption has been increased and readily used and accepted by faculty for academic purposes [7]. Aydin, D'Esposito and Gardner concluded that studies indicate that internet makes life easy and connects different communities and cultures[8,9].To measure the thoughts of faculty regarding Internet usage, F-Test which is a statistical test is found to be appropriate. Statistical variance shows the way to compute the scatteredness in data and helps to determine the attitude of users involved in the analysis. F-Test is the popular frequency test introduced to test the frequency distribution of any given data items in sample. FTest is used to compare the variance of two populations. If calculated $(F)$ value >observed value (F critical onetail), then we reject the null hypothesis otherwise accept. Paul J. Lavrakas described that an F-Test is any statistical hypothesis test whose test statistic assumes an $\mathrm{F}$ probability distribution. F-test is frequently associated with analysis of variance (ANOVA) and is most commonly used to test the null hypothesis. The Ftest was devised as an extension to the Z-test but F-test has a distinct advantage over the Z-test because multiple independent groups can easily be compared [10]. Chaman Verma and Sanjay Dahiya concluded found statistically significant difference in scatteredness in student's thought regarding usage of Internet in relation to 
gender basis and locality basis [11]. Murat TUNCERa, Yunus D O ANb, Ramazan TANA c described that the use of Internet for education and research is very essential. Internet is used in teaching, research, social interaction, communication and exchange of information [12].

\section{OBJECTIVES AND HYPOTHESIS}

This study sought to discover variances of faculty's attitude towards Internet Usage in various educational institutions of Sirsa district, Haryana.

1. To discover out the scatteredness in faculty's thoughts regarding Internet usage on gender basis.

2. To achieve the above objective null hypothesis is described below:

H01: There is no significant difference in difference between scatteredness in faculty's thoughts regarding Internet in relation to their gender.

\section{DESIGN AND METHODOLOGY}

A questionnaire is prepared according to Psychometric Likert type scale which is distributed amongst male and female faculty of different colleges and universities in Sirsa district, Haryana. A stratified random sampling method is used to collect the samples. A structured Questionnaire is designed as per the objective keeping in mind that faculty's thoughts are to be analysed in the study, regarding internet usage in their social, academic and personal lives.

\subsection{VARIABLE SELECTION}

The present study includes one independent and twenty dependent variables. In this paper Gender is considered as independent variable and dependent variables are chosen according to social, personal and academic outlook of faculty.

\subsection{INSTRUMENT DESIGN}

In the present study, a questionnaire is designed to find out variances in faculty's thoughts towards Internet usage in academics, social and their personal lives. IAS (Internet attitude scale) is used in 5 point Likert format. This instrument consisted of 20- items scored on a 5 point Likert type scale (strongly disagree=1, disagree $=2$, undecided $=3$, agree $=4$, and strongly agree $=5$ ).

\subsection{POPULATION IDENTIFICATION}

The faculty members are from different fields. Table 2 shows that there are $52.6 \%$ male and $47.4 \%$ female faculty. Table 3 shows that $48.2 \%$ are from arts field and $51.8 \%$ are from science field. Table 4 gives graphical representation of institute wise distributions of participants. There is one university and rest other are colleges. There are $26.3 \%$ of participants from CDLU(Ch. Devi Lal University), $15.8 \%$ of them from GNC(govt. National college), $7 \%$ from LHP(Hansraj Phutela Law College), 19.3\% from JCDM(JCD Memorial College ), $22.8 \%$ from JCDMCOE (JCD Memorial College Of Engineering) and 8.8\% from JCDIBM (JCD Institute Of Business Management).

TABLE I. Institute Wise Population Distribution

\begin{tabular}{|c|c|c|c|c|c|c|c|}
\hline \multicolumn{7}{|c|}{ Participated Institutions } & \multirow{2}{*}{ Tolleges } \\
\cline { 1 - 7 } & University & \multicolumn{7}{|c|}{ Total } \\
\cline { 1 - 7 } & CDLU & GNC & LHP & JCDM & JCDMCOE & $\begin{array}{c}\text { JCD } \\
\text { IBM }\end{array}$ & \\
\hline N & 30 & 18 & 8 & 22 & 26 & 10 & 114 \\
\hline$\%$ & 26.3 & 15.8 & 7 & 19.3 & 22.8 & 8.8 & 100 \\
\hline
\end{tabular}

(Source: Authors)

\subsection{SAMPLING}

The study uses stratified random sampling method is used to collect primary data. A total of 114 faculty members from different institutions of Sirsa district, Haryana have participated in the study. 


\subsection{Statistical TeChNiQues}

To find out the variances in thoughts of faculty towards Internet usage frequency test (F-test) is applied. To determine significant difference among faculty outlook in relation to their gender, independent sample Faculty f-test is applied. In present study the analysis of faculty filled score is done by adding tool packs in Microsoft Ms-Excel 2010 named as Analysis Toolpack and Analysis Toolpack-VBA. Various tables were made using different functions like count (), average () and stdev().

\subsection{GENDER WISE OUTLOOK ANALYSIS:}

\section{DATa ANALYSIS}

In this section results have been found regarding evaluate outlook of faculty in relation to their gender. Faculty Outlook towards Internet awareness has been compared in terms of gender. The results of the independent group's t-test which compares the faculty outlook towards Internet awareness in relation of gender variable have been given in Table-3.

TABLE II. Individual Variables Testing Using F-Test

\begin{tabular}{|c|c|c|c|c|c|c|c|}
\hline \multirow[t]{2}{*}{ Attributes } & \multirow[t]{2}{*}{ Dependent Variable } & \multicolumn{2}{|c|}{$\begin{array}{l}\text { Male } \\
\mathrm{n}=60\end{array}$} & \multicolumn{2}{|c|}{$\begin{array}{c}\text { Female } \\
\mathrm{n}=54\end{array}$} & \multirow{2}{*}{ 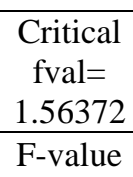 } & \multirow{2}{*}{$\begin{array}{l}\text { Hypothesis } \\
\text { Status } \\
\text { (Accepted/ } \\
\text { Rejected) }\end{array}$} \\
\hline & & Mean & $\mathrm{Sd}$ & Mean & $\mathrm{Sd}$ & & \\
\hline \multirow{4}{*}{$\mathbf{S}_{\text {OUT }}$} & $\begin{array}{l}\text { 1.Internet helps to improve Indian academic } \\
\text { growth }\end{array}$ & 4.2 & 0.732 & 4.1 & 0.492 & 2.21543 & Rejected \\
\hline & 2. Internet is good social media. & 4.3 & 0.761 & 4.1 & 0.61 & 1.55844 & Accepted \\
\hline & 3.Internet promotes cyber crime & 3.7 & 0.911 & 4.0 & 0.858 & 1.12879 & Accepted \\
\hline & $\begin{array}{l}\text { 4.Internet is harmful for our educational } \\
\text { society }\end{array}$ & 2.0 & 1.149 & 2.1 & 0.96 & 1.43415 & Accepted \\
\hline \multirow{5}{*}{$\mathbf{A}_{\text {OUT }}$} & 5.I use Internet to prepare my lecture notes & 4.1 & 0.804 & 3.9 & 0.784 & 1.05419 & Accepted \\
\hline & 6.Internet act as digital library of e-books & 4.2 & 0.755 & 4.2 & 0.541 & 1.94729 & Rejected \\
\hline & 7.Internet is play a major role as research tool & 4.6 & 0.622 & 4.6 & 0.592 & 1.10400 & Accepted \\
\hline & $\begin{array}{l}\text { 8.I think Internet is easy to use as compare to } \\
\text { Library }\end{array}$ & 4.0 & 0.688 & 3.8 & 1.065 & 0.41718 & Accepted \\
\hline & 9.I motivate my students to learn Internet & 4.3 & 0.537 & 4.2 & 0.528 & 1.03367 & Accepted \\
\hline \multirow{11}{*}{$\mathbf{P}_{\text {OUt }}$} & 10.Internet is wastage of time and efforts & 1.8 & 0.804 & 1.8 & 0.718 & 1.25489 & Accepted \\
\hline & $\begin{array}{l}\text { 11.I do not like Internet due lack of } \\
\text { knowledge. }\end{array}$ & 1.9 & 1.005 & 1.9 & 0.744 & 1.82672 & Rejected \\
\hline & 12.Internet is great hub of useful Information & 4.7 & 0.454 & 4.6 & 0.502 & 0.82083 & Accepted \\
\hline & 13.I think Internet is not easy to learn & 2.2 & 0.963 & 2.1 & 0.825 & 1.36225 & Accepted \\
\hline & 14.I forgot time while using Internet & 3.4 & 1.207 & 3.1 & 1.139 & 1.12177 & Accepted \\
\hline & 15.I am confident while using Internet & 4.2 & 0.547 & 4.1 & 0.516 & 1.12507 & Accepted \\
\hline & $\begin{array}{l}\text { 16.I think Internet is best communication } \\
\text { media }\end{array}$ & 4.3 & 0.71 & 4.0 & 0.727 & 0.95391 & Accepted \\
\hline & 17.I use Internet in my mobile & 4.1 & 0.999 & 4.0 & 0.911 & 1.20148 & Accepted \\
\hline & 18.I think Internet is source of entertainment. & 4.1 & 0.787 & 3.9 & 0.529 & 2.21548 & Rejected \\
\hline & 19.I use Internet to read newspaper & 3.4 & 1.025 & 3.0 & 1.098 & 0.87030 & Accepted \\
\hline & $\begin{array}{l}\text { 20.I use Internet at my home and } \\
\text { College/University }\end{array}$ & 4.4 & 0.673 & 4.3 & 0.5 & 1.81116 & Rejected \\
\hline
\end{tabular}

*(Social Out Look (Sout), Academic Outlook (Aout), and Personal Outlook (Pout))

(Source: Authors) 


\subsection{GENDER WISE TESTING OF HYPOTHESIS:}

Table 2 shows the result of F-test for each dependent variable which is conducted on male and female faculty. The first four dependent variables are part of the attribute $S_{\text {OUT }}$ (Social Outlook), next five dependent variables come under $\mathrm{A}_{\mathrm{OUT}}$ (Academics Outlook) and the remaining is part of $\mathrm{P}_{\mathrm{OUT}}$ (Personal Outlook).

- Observations: MALE (N=60) and FEMALE(N=54)

- Degree of Freedom: MALE(df=59) and FEMALE $(\mathrm{df}=53)$

- Calculated $\mathrm{F}$ values are given in the table.

- F Critical one-tail: Observed $F=1.56372$

It is revealing from table 3 that for a wide number of variables, hypothesis $\mathrm{H} 01$ is accepted. For variables $1 \mathrm{st}, 6^{\text {th }}, 11$ th, 18 th and $20^{\text {th }}$, the hypothesis is rejected as $\mathrm{F}>\mathrm{F}$ Critical which is not satisfying the hypothesis. The hypothesis is accepted for the variables numbered as $2^{\text {nd }}, 3^{\text {rd }}, 4^{\text {th }}, 5^{\text {th }}, 7^{\text {th }}, 8^{\text {th }}, 9^{\text {th }}, 10^{\text {th }}, 12^{\text {th }}, 13^{\text {th }}$ $, 14^{\text {th }}, 15^{\text {th }}, 16^{\text {th }}, 17^{\text {th }}, 19^{\text {th }}$ as value of $\mathrm{F}<$ Critical which satisfies the individual hypotheses.

TABLE III. Overall Analysis Using F-Test

\begin{tabular}{|l|r|r|}
\hline \multicolumn{1}{|c|}{ Group } & \multicolumn{1}{c|}{ Male } & \multicolumn{1}{c|}{ Female } \\
\hline Mean & 3.68 & 3.591019 \\
\hline Variance & 0.89531 & 0.825665 \\
\hline Observations & 20 & 20 \\
\hline df & 19 & 19 \\
\hline F & 1.08435 & \\
\hline P(F<=f) one-tail & 0.430868 & \\
\hline $\begin{array}{l}\text { F Critical one- } \\
\text { tail }\end{array}$ & 2.168252 & \\
\hline
\end{tabular}

- Observations: Male $(\mathrm{N}=60)$ and Female $(\mathrm{N}=54)$.

- Degrees of Freedom: Male (df=59) and Female (df=53).

- F : Calculated $\mathrm{F}=1.0236$

- P: probability that the observed difference in variance between male and female results from random error.

- If $\mathrm{P}<0.05$, variances are statistically different. Here it is 0.430868 .

- F Critical one-tail: Observed F=2.168252.

Table 3 shows that $\mathrm{F}<\mathrm{F}$ Critical $(1.08435<2.168252)$ value at $5 \%$ level of significance is not significant which satisfies the hypothesis $\mathrm{H} 01$ and proves that there is no significant difference between scatteredness in faculty's thoughts regarding Internet in relation to their gender. Hence null hypothesis H01 "There is no significant difference in difference between scatteredness in faculty's thoughts regarding Internet in relation to their gender" is failed to reject.

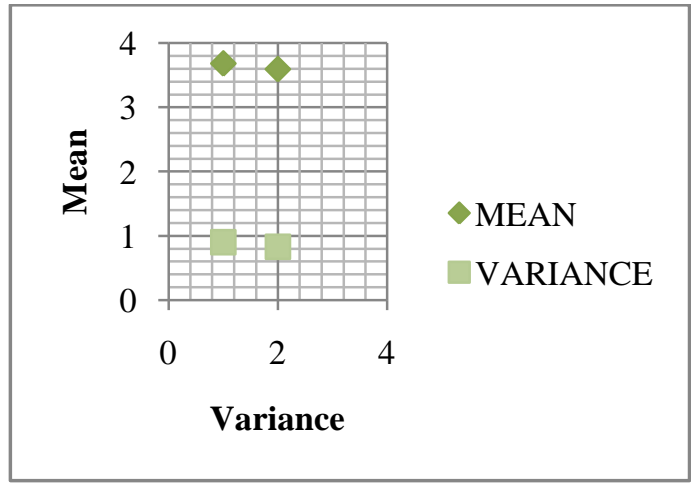


Fig. 1: Distributed Cognitive Model on Gender basis

(Source: Author)

The above Fig. 1 shows scatteredness of of mean and variance in relation to gender variable of faculty. The $\mathrm{X}$-axis shows variance value and $\mathrm{Y}$ - axis represents mean value for them. The data from above graph evident that no meaningful variation between scatteredness in faculty's thoughts regarding Internet in relation to their gender due to nearby value (mean and variance ) of male and female faculty towards Internet. Hence, it reveals gender variable did not affect scatteredness between male and female faculty towards Internet communication. Thus, authors have entitled this study as distributed cognitive approach.

\section{CONCLUSION}

This study has statistically tested various variables and has given the results accordingly. The results support that Internet is a good social media, helps to prepare lectures, is a good research tool, motivates students and is overall a great hub of useful information. The male and female faculty have responded positively to a great number of variables. They use more of internet in their social, academic and personal lives. The outcomes of this paper are revealing that there is no scatteredness among thoughts of faculty towards Internet usability. Even faculty has also supported some of the variables which showed that internet also promotes cyber crime and is also harmful for our educational society. But more of the acceptance to variables has revealed that their attitude is positive towards Internet usage. The results of this study also give us suggestions that the availability of internet should be increased at educational places and new technologies should be readily adopted as internet is actively being used by faculty for educational purposes. The technologies should be adopted and updated not only in Sirsa district but also in other districts of Haryana district.

\section{ACKNOWLEDGMENT}

The authors would like to thank administrations of all participated Institutions for providing such as a wonderful support to the completion of this study. In addition the authors would also like to extend their thanks to all the faculty members.

\section{REFERENCES}

[1] Internet society report 2015, http://www.internetsociety.org/globalinternetreport/assets/download/IS_web.pdf Accessed on 15 January 2016.

[2] India to have second largest internet base in Dec 2015, http://yourstory.com/2015/11/india-internet-user-base-2015/ Accessed on 16 January 2016.

[3] T. Nazir, "Use and adequacy of e-resources by the research scholars and students of the University of Kashmir in science \& social science faculties: a case study by", Brazilian Journal of Information Science: Research Trends, 9(1), 2015, 1-16.

[4] M. Tsvere, T. L. Nyaruwata and S. Swamy, "Internet Usage by University Academics: Implications for the 21st Century Teaching and Learning", International Journal of Science and Research, 2(9), 2013, 19-25.

[5] M. K. Sinha, S. Bhattacharjee and S. Bhattacharjee, "A Study on ICT Literacy and Internet Use Pattern among College Library Users of Barak Valley, South Assam, North East India", Current Trends in Technology and Science, 2, 2013, 301-316.

[6] R.Kumar and A. Kaur, "Internet Use by Teachers and Students in Engineering Colleges of Punjab, Haryana, and Himachal Pradesh States of India: An Analysis", Electronic Journal of Academic and Special Librarianship, 7(1), 2006.

[7] A.Alshawi and A. Alwabil, "Internet Usage by Faculty in Saudi Higher Education", IJCSI International Journal of Computer Science Issues, 10 (3), 2013, 81-87.

[8] S. Aydin, "Attitudes of EFL learners towards the Internet", The Turkish Online Journal of Educational Technology, (6)3, 2007, 1826.

[9] J. E. D'Esposito, and Gardner, R. M., "University students' perceptions of the Internet: An exploratory study", The Journal of Academic Librarianship, 25, 1999, 456-461.

[10] R. Nachmias, D. Mioduser and A. Shemla, "Internet usage by students in an Israeli High school", Journal of Educational Computing Research, 22(1), 2000, 55-73.

[11] C. Verma and S.Dahiya, "Scatteredness in Student's Thoughts towards Internet Usage in Educational Life", International Journal of advance technology in engineering and science, 3(1), 2015, 546-553.

[12] M. Tuncera, D.O. Yunus and C.T. Ramazan, "Vocational School Students' Attitudes Towards Internet", Proc. 13 ${ }^{\text {th }}$ International Educational Technology Conf. - Social and Behavioral Sciences , 103, 2013, 1303- 1308. 